\title{
Accessibility, Diversity and Inclusion in Events
}

\section{Rebecca Finkel and Katherine Dashper}

\section{Introduction}

This chapter explores the importance of issues concerning accessibility, diversity and inclusion in events discourses and praxis. These are broad terms encompassing a multitude of facets related to social, cultural, economic and political approaches and interactions. We recognise that individual events have distinct issues to explore; however, we intend to provide a general discussion about these three interlacing topics in order to provide a platform for further debates and improved applications in events landscapes.

Until recently, much of existing events literature has concentrated on measuring and evaluating impacts on communities and places (see Langen \& Garcia, 2009; Morgan \& Condliffe, 2008; Preuss, 2007; Wood, 2005). Within these mainly economic-driven contexts, research has, for the most part, prioritised narratives of dominant cultures and privileged groups. As Finkel et al. $(2018,1)$ argue, "Although there has been a recent swell of media attention and public interest in this area, research focusing on non-hegemonic populations as they relate to events environments still is in need of further exploration... It is only recently that issues of under-representation, marginalisation, and intolerance have begun to emerge in the critical events discourse." A 'turn' in events studies research can be seen to be taking place as critical event studies gains momentum, drawing from cross-disciplinary literatures and cross-fertilising with broader social science approaches and methodologies. This has meant that more and more events are being viewed through gender lenses (e.g. Dashper, 2018; 2019; Finkel, 2014; 2015), critical race lenses (e.g. Fletcher \& Hylton, 2018), disability lenses (e.g. McGillivray et al., 2017; Misener et al., 2015), and from different points of view to highlight less conventional power relationships (e.g. Duffy et al., 2018; Walters \& Jepson, 2019). This chapter aligns with critical event studies, which seeks to "set an agenda for ethical management, governance, and coexistence with the wider external world" (Robertson et al., 2018, 865), by exploring the ways that accessibility, diversity, and inclusion can be developed and enhanced in research, in industry, and in overall awareness.

The following sections concentrate on each topic individually; however, we acknowledge that these concepts and corresponding experiences do not exist in silos. They are interrelated and entangled, and the boundaries between them can often become blurred, especially with regard to event design, programming, production, and consumption. Yet, we believe it is important to analyse each in-depth separately, as well as to illustrate the ways they intersect, to gain a greater appreciation of how they impact on the contemporary events environment.

It is through better understanding of accessibility, diversity, and inclusion that advances in events can be achieved for the benefit of more people and communities. In order to guide the following discussion and show how these concepts relate to different aspects of event design, management, and experience, we discuss accessibility in terms of 'getting involved', diversity in terms of 'who can be involved', and inclusion as 'how involvement can be realised'. A worthy goal for all events is to be inclusive - to welcome everyone and enable them to participate fully, on their own terms - and to achieve inclusivity, issues of accessibility and diversity need to be addressed. 


\section{Accessibility - Getting involved}

Accessibility is the first step towards an inclusive society; one where all groups and individuals can play an active and meaningful role. Accessibility needs to be considered on multiple levels from the physical, to the social, cultural, economic and, often, political. As Finkel et al. $(2018,2)$ suggest, "Accessibility can be understood in terms of the measures put in place to address participation by those with impairments, both permanent and temporary, as well as both physical and mental, including perceived class and cultural barriers." One of the main questions when considering access in events is; does the event space and design allow all to participate? And, if not, why not and who is influential in making it that way? Accessibility is complex and context-specific, and what may appear to organisers to be accessible in terms of physical environment or pricing, for example, may not be so from the perspective of some people with specific needs or constraints that affect their involvement with the event. Consequently, when assessing accessibility event organisers need to consider issues from a range of positions and try wherever possible to include different stakeholders and representatives of potentially-marginalised groups in those assessments.

Being able to navigate an event space is the most conspicuous type of accessibility there is. Event spaces must be comfortable, safe, and non-threatening for attendees as a bare minimum. In the UK, access for disabled people to and in event sites can fall under the Equality Act 2010, which sets out a duty to make reasonable adjustments if a person with impairments is placed at a substantial disadvantage compared with non-disabled people or people who do not have their disability. It is unlawful discrimination if someone does not cooperate with their duty to make reasonable adjustments under this Act. In events contexts, the duty to make reasonable adjustments applies to employees as well as attendees. In most cases, this involves changes to the physical environment, which can include, but is not limited to:

- providing ramps and stairway lifts

- providing more space on pathways and between furniture for maneuverability

- making doorways wider

- installing automatic doors

- providing more lighting and clearer signs

- disabled toilets and facilities

- comfortable (larger) seating

- portable induction loop for people with hearing aids

- BSL interpreters and/or captioning

- providing information in alternative formats, such as Braille or audio platforms

- providing information, such as transport, parking, and facilities, online in digitally accessible manner to set expectations about what is and is not available

- clear booking system

- free attendance for carers

- extra staff assistance

This can incur additional costs for events organisations, as disabled people are not liable to pay for these adjustments; thus, it needs to be factored into event budgets and operating costs, and associated costs can often be viewed as a deterrent to making events more 
(physically) accessible. There are a wide range of impairments which may affect individuals' ability to access event spaces, and, consequently, making an event physically accessible to everyone is a complex proposition, but one that requires careful consideration and investment if events are to be available to all.

Understanding the complex requirements of individuals with different impairments and needs is difficult, and event organisers may benefit from working with charities and other organisations to support their efforts to be more physically accessible. The disability-led charity, Attitude is Everything, is a UK-based organisation which seeks to improve Deaf and disabled people's access to live music events and, according to its website, "works with venues and festivals to translate the Equality Act 2010 into accessible good practice guidance for service providers." One of the primary ways they do this is through their Venue and Festival Charter of Best Practice, to which 160 venues and festivals across the UK have currently signed up. The Charter "helps the music industry to understand the requirements of Deaf and disabled people at live music events by building equality into the strategic process. The ethos of the Charter is that Deaf and disabled people should be as independent as they want to be at live music events" (Attitude is Everything Venue and Festival Charter of Best Practice, 2016).

Increasingly, there also has been more awareness about invisible disabilities and how they can impede event experiences for both attendees and performers, and many events are providing additional resources to support attendees. Some festivals, for example, have designated 'chill out zones' for those with anxiety and who are neurodiverse to feel comfortable in crowded event spaces, as well as additional staff on hand to help if people are feeling panic or other difficulties (Snapes, 2019). The Edinburgh Festival Fringe is one of the prime examples of an events organisation taking accessibility issues of this kind seriously. Although the Fringe Society, which is the operating organisation for the festival, cannot regulate performance venues in the city, many of which are not accessible for all needs, they actively work with venue managers to increase accessibility features in efforts to incorporate as many access requirements as possible given the restrictions that older buildings (e.g. uneven stairs) and an older city (e.g. cobblestones) bring. For performers, the Fringe Society has created an open guide to putting on an accessible show, which is available on their website. The guide contains "tools to make small changes which will have a huge impact: What you need to know about captioning shows. How to get started with creating a touch tour. What to consider if you're planning a relaxed performance" (Edinburgh Festival Fringe, 2019). For potential attendees to the festival, the Edinburgh Fringe box office has specially dedicated staff for access enquiries and ticket bookings. Many shows offer captioning, audio description, signed and relaxed performances, which potential attendees can find by searching with these filters on their website. In terms of navigating the city during the festival, there are five Changing Places accessible toilets in central Edinburgh during August. Additionally, The Fringe Society has 80 sensory backpacks which are available to borrow, free of charge, for autistic children and adults. Each sensory backpack contains a fidget toy, earplugs or ear defenders, a photo story describing the street events, and a list of relaxed performances at the Fringe. Smaller backpacks for children also include a cuddly toy. This scheme has been praised by disability campaigners and is in the process of being rolled out at other festivals around the UK (Euan's Guide, 2019). 
It is not only festivals that are concerned with accessibility for people with impairments and disabilities. The MICE industry, encompassing conferences and business events, is also focusing on issues related to unrestricted attendance. A study by Rodríguez-Zulaica \& Fernández-Villarán Ara (2018) found that more events staff in Europe are receiving equality and diversity training in order to assist customers as well as re-configuring their event spaces to be more physically accessible. However, conferences can still be experienced by many as exclusionary spaces, including those who may not have disabilities themselves but have caring responsibilities. Thus, Henderson (2018) argues the priority needs to be how to facilitate access within as well as access to events. She gives the example of inflexibility of conference schedules to illustrate how there can be barriers to participating fully in a conference. Walters (2018) suggests a tripartite approach to improve accessibility in conference organisation, centring on physical accessibility, financial accessibility, and cognitive accessibility (i.e. mental and emotional wellbeing). She found that adopting this three-pronged approach facilitates diversity and fosters an inclusive environment, which has benefits for all conference delegates.

Although physical mobility and ability to manoeuvre around events spaces safely and comfortably is important, it is not the only potential barrier to accessibility. Less tangible aspects, such as perceptions and beliefs, can also have an impact on access. Such perceptions can assist or hinder involvement in and enjoyment of the event experience, regardless of the technical legality of operations or any reasonable physical adjustments that are made. Barriers to access that may not be overtly visible include, but are not limited to, mental wellbeing, financial costs, and event programming content alignment with cultural values. Also, how certain individuals or communities perceive their safety at an event can have an impact on their sense of belonging and whether or not they feel welcome and comfortable in event spaces. Additionally, other members of the audience at an event need to be considered, as this may have a significant impact on whether people feel they belong at an event and are comfortable sharing the space with other attendees. This intersects with issues related to class, ethnicity, age, gender, sexualities, and other psycho- and sociofactors. By being aware of such issues, event managers have the power to reinforce or challenge beliefs about participation and have the potential to develop audiences for their events. This may be especially the case with regard to arts and cultural events, which are often considered more complex due to traditional barriers based on taste and status (Bourdieu, 2010).

In the past, cultural forms were almost always classified as either 'high' or 'popular' based on the social characteristics of people attending such events. This was primarily based on the practice of upper classes attending 'high' cultural events, such as opera and classical music concerts, to display their status in society. This split was reinforced by education and class perceptions, which furthered socially constructed limitations on cultural interest and exposure. Previously, wealth and education were the main avenues to the appreciation of high cultural forms. It has been argued that many people from working class or underprivileged backgrounds often felt inferior and intimidated when faced with the high arts and the prestigious cultural institutions that housed them (McGuigan, 1996). Therefore, they avoided them, which reinforced deeply set class notions and the image of certain cultural events as elitist. These perceptions were reproduced by family and schools, and children learned from an early age what kind of events were 'for them' and which were not (ibid). 
Indeed, it has been argued that it was not popular culture that prevented people from taking an interest and participating in high cultural events, as many critics believed to be the case, but the absence of the prerequisite background and lack of opportunity to obtain it (Gans, 1999).

In recent decades, however, the distinction between high and popular forms is becoming less stark, and there is less of a prevailing sentiment of who should attend certain cultural events. This is especially the case in the UK, where governmental and cultural bodies are increasingly promoting widening access to many different types of cultural activities among the population by supporting educational campaigns and implementing incentives for people to attend many cultural events. For example, free opera performances and classical music events in parks and public spaces, discounted and subsidised theatre tickets, and free admission to museums are examples of this attempt at improving access. Frey (2000) argues that many people attend festivals because they provide a more welcoming atmosphere than venue-based events. He suggests that some people may feel threatened in opera houses or performing arts halls, but the venues used for most festivals, such as public spaces, popular meeting places, and sporting stadiums, convey a more accessible environment for a diverse range of people.

Most UK cultural organisations are actively trying to rid cultural venues of their elitist connotations in order to increase access and participation. Many venues, such as opera houses and theatres, now present all kinds of cultural events from different genres and time periods. Often, the audience demographics are similar for these varied performances. In fact, it is suggested that people with higher incomes now tend to participate in a variety of different cultural activities rather than substituting only one type for another (Caves, 2000). Due to audience development potential, cultural institutions that embrace many different types of cultural forms are seen to be more economically successful (Strom, 2002). It has been suggested that high culture institutions bring prestige to cities, but often do not attract large enough audiences to generate profits. Although popular culture organisations are more commercially viable, they are less likely to acquire political support and be considered symbolically important to the city. Cultural institutions now have the opportunity to link aesthetic-minded credentials with financially-driven activities by presenting diverse cultural events (ibid). For example, the Royal Ballet has performed a ballet set to the rock music of Jimi Hendrix; and Glyndebourne Opera is also engaging in this kind of boundary blurring activity. Primarily regarded as conservatively exclusive and prohibitively expensive, Glyndebourne made an effort to reposition its image by staging a 'hipopera' or rap music version of Mozart's Cosi Fan Tutte set in a London council housing estate car park. This performance was part of an attempt to widen outreach, make the arts more accessible, and engage young people and new audiences.

The vast majority of strategies to improve accessibility involve event cost and event programming. High ticket prices can be a barrier, which is why many festivals include free events, such as the The Free Fringe, which is an organisation that promotes free shows during the Edinburgh Festival Fringe. Other types of events and festivals have promotions, incentives, and discounts, especially for concessions, in order to encourage attendance. The crux lies in the balance between making prices affordable and making the event financially sustainable. Attracting new and wider audiences is also a priority for many events and 
festivals, and this hinges on programming content. According to Finkel's (2009) study on UK arts festivals, almost half of the festivals surveyed do not try to attract a specific target audience and, instead, aim for a broad appeal. This can be seen to be in keeping with broader government and arts organisation policies for improving accessibility and emphasising social inclusion in cultural events. Of those that design programming content with particular sections of the population in mind, youth and ethnic minorities were the two groups the majority of UK arts festivals aimed to attract in order to develop new audiences. This also can be seen to be aligned with government agendas for supporting diverse audiences as well. Some festivals are supported by local councils as part of community focus schemes to improve accessibility and diversity in the arts; however, Finkel (2009) also found that the majority of UK arts festivals foster arts education and involvement among local populations at their own expense. Smaller festivals in rural locales especially provide a social service by including an educational element and arranging for artists to visit schools, churches, and libraries. Often, this is the only access students in these areas have to professional musicians, as most schools do not have the resources to fund special trips or support music education. Festivals that engage in such accessible and community-focused activities are often well supported by locals in terms of volunteers, donations, participation, and praise for the organiser's efforts. Arts festivals not only have the potential to be entertaining and improve people's quality of life, but they also can provide a framework for arts education and appreciation and can encourage people to engage in social responsibility for their communities. In this regard, they can be seen to have the potential to strengthen individuals' connections to place by encouraging community interaction and strengthening ideas of local identity (Newbold et al., 2019).

Many events, and perhaps some 'high' culture events particularly, can be seen as inaccessible to people from non-dominant cultures. The Edinburgh Fringe Festival is making efforts to be more accessible in terms of price and physical environment, as discussed above, but in terms of 'race' and ethnicity it remains a space of 'overwhelming whiteness', according to Jessica Brough, founder of Fringe of Colour, who is aiming to make the monthlong event more welcoming to young local people of colour, in an attempt to diversify audiences. Previous performers at the festival have explained the isolation they have felt in facing predominantly white audiences, as well overt discrimination from venue staff, security, and audiences. Building on the work of the Black Ticket Project, which provides young black people with free tickets to theatre shows, Fringe of Colour is an attempt to encourage more people of colour to attend the event, diversifying audiences and beginning to shift the culture away from the dominant white norm. Working with seven venues, the initiative provides young local people of colour with free tickets to specific performances (Wolfe-Robinson, 2019).

Making events truly accessible to all is complex, and our brief discussion here indicates just how inaccessible events often are, when the notion of 'accessibility' is taken to include a wide range of factors relating to physical space, programming, atmosphere, culture, pricing, and management. Putting in measures to try and improve accessibility on these grounds is important, but accessibility alone will not ensure inclusion, and in the next section we consider how the diversity of who is involved in events - as performers, organisers, workers, and audiences - plays an important role in helping transform accessibility into inclusion. 


\section{Diversity - Who is involved}

Accessibility and participation are very much linked. Who is allowed - and also who feels comfortable - getting involved in an event is a sign of the levels of accessibility. Too often, events have been dominated by social, cultural, and economic elites, and lack of diversity has hindered accessibility and inclusion of other groups. According to Finkel et al. $(2018,2)$, "Diversity can be taken to mean individual and community diversity, such as those relating to gender, sexualities, ethnicity, age, religion, and so forth. It also refers to the range of different events being studied." As with accessibility, diversity issues within events are complex and broad and in this section we consider diversity in relation to three groups of who is (or is not) involved in events: 1) performers; 2) organisers and workers; and, 3) audiences.

It matters who is seen to be playing active, front-facing roles at events as performers and exhibitors, as this acts as a powerful visible statement about who is valued within the context of that event and community. If individuals do not see people 'like them' - in terms of things like gender, 'race', sexuality, disability and age - then they may not think that the event is a welcoming space for them and may decide it is not worth aspiring to similar positions themselves. Role models matter, particularly for under-represented groups (Burke et al., 2006; Meier, 2015). Role models are important on three levels: first, they act as behavioural models, showing us how we can learn particular skills and practices needed to succeed in a given context; second, they act as representations of what is possible, showing that if a person like them can achieve something, so can another person from that group or community; and, third, they act as inspirations, helping to encourage others to stretch themselves and dream big (Morgenroth et al., 2015). Consequently, if most of the performers and stars of events represent only narrow, elite groups, others may feel that such events are not welcome spaces for them.

Music festivals have often been criticized for the narrow profile of key performers, particularly on grounds of gender. In 2018, BBC Reality Check analysed the line-ups of the nine largest UK music festivals to assess gender representation and balance, and found stark disparity. Out of 756 acts, $77 \%$ were all male, another $9 \%$ were groups with more male than female members, and just 13\% of acts were all female (BBC News, 2018). The Keychange 50:50 festival pledge, led by the PRS Foundation, aims to redress this imbalance. It was launched in 2018 and a year later had more than 190 music festivals globally signed up to achieve equal gender representation in line-ups by 2022. In June 2019, this was extended to include other organisations in the music industry, such as conservatoires, orchestras, and concert halls. The Resonate database, which documents orchestral works commissioned by British orchestras in the last 25 years, showed that just $13 \%$ of these works were commissioned from female composers (PRS Foundation, 2019). The lack of gender diversity in all forms of music performance events, in and beyond the UK, is representative of ongoing gender inequality in the music industry and reinforces the sense that music is men's domain, with women only permitted as audience members or, occasionally, supporting acts. Initiatives like Keychange 50:50 show that this lack of diversity is finally being recognised as problematic and will hopefully lead to change. However, there is a long way to go to achieve equal gender representation in terms of performers at music events.

The broader creative and cultural industries are strongly dominated by social elites - mainly white, middle/upper-class men - making it much more difficult for those from underprivileged 
and underrepresented groups to gain positions in theatre, TV, journalism and associated sectors (O'Brien et al., 2016). This is reflected in lack of diversity across cultural events, whether diversity is considered in terms of gender, 'race' and ethnicity, class, (dis)ability, sexuality, or religion. This lack of diversity can make creative events feel unwelcoming to people from minority communities and can lead to cultures of intolerance and hostility towards underrepresented groups, affecting accessibility and thus inclusion. These are serious, ingrained issues that require systematic change to promote and enable wider diversity, but some companies and events are actively trying to change things on a more local level. For example, the Consortium of Asian American Theaters and Artists works to support the Asian American theatre community, supporting collaboration and organising networking events, to achieve their mission which "envisions a strong and sustainable Asian American theatre community that is an integral presence in national culture" (CAATA, n.d.). Such initiatives have a role to play in supporting performers from minority groups in navigating the often closed and exclusive environment of cultural events, which may, over time, change the representation of performers seen at these events.

It is not just music, arts, and cultural events that show a lack of diversity in terms of performers/speakers. The MICE industry has also come under criticism for lack of diversity in terms of keynote speakers and panelists. The default 'expert' speaker remains a white, middle class man. Social media has proven a powerful platform to call out the lack of diversity in conference panels, with the 'Congrats, you have an all-male panel!" account on tumblr actively highlighting lack of gender diversity. The hashtag 'manel' has been coined for the phenomenon, pointing to the widespread practice of events engaging all male (and usually all white) speakers. This increased attention on social media platforms illustrates discomfort and frustration with the inequality of the prominence of all male panels at academic and corporate conferences (Platt \& Finkel, 2018). A survey by software company Bizzabo found that men outnumbered women as event speakers two to one over the last five years. Their analysis included 60,000 speakers at mostly private events in 23 countries, and they found that $69 \%$ of speakers were male. Women were most often seen as speakers at fundraisers, galas, and social gatherings, but much less likely to speak at conventions, meetings, and conferences. They also found that, despite widespread social media discussion around the issue, gender diversity in terms of speakers at events is barely changing, with only a $2 \%$ increase in women speakers in the last two years (Fadel, 2018). Some individuals now refuse to speak at an event with an all male panel or an all white panel, but the issue continues to be widespread across the MICE sector.

Lack of diversity is also problematic in terms of who organises and works at events. A survey conducted by BCDME (2017) found that only $27 \%$ of CEOs and MDs in the UK events industry are female, despite women making up the majority of the industry numerically. A glass ceiling persists in the events industry, meaning that women are underrepresented at senior levels. The reasons for this are complex, but relate to masculine work cultures and practices, long unsociable working hours, incompatibility between childcare and senior management, frequent need for travel, and old boys' networks that perpetuate male dominance of strategic positions (Dashper, 2013; Dashper \& Finkel, forthcoming). The limited number of women in senior positions is an issue in terms of inspiring younger women in the industry. Given that approximately $80 \%$ of students on events management degree programmes are female, shortage of visible female role models in leadership positions is 
problematic in terms of encouraging other women to aspire to senior roles (Thomas, 2017).

Gender inequality in the workplace is a deep rooted and systemic problem that affects most sectors of the economy, not just the events industry, and has proven remarkably difficult to overcome (Padavic et al., 2019). Real change will require concerted effort on a global scale to change attitudes, dominant cultures, ways of working, and social support systems. Some events companies are acting locally to try and support women in the sector and overcome some of the barriers to progression they face in their individual careers. In the UK, the Fast Forward 15 mentoring programme is one such initiative, and has produced impressive results for the women involved as mentees (Dashper, 2018). Such local initiatives are important and show how targeted practices can support women and promote gender diversity in the sector, even if they do not address the more pervasive aspects of gender inequality that continue to shape the careers of all workers in the events industry (Dashper, 2019).

The events industry is also beset by lack of diversity in terms of 'race' and ethnicity, remaining a predominantly white space in terms of senior management and leadership positions (Fletcher \& Hylton, 2018). The same is true in terms of class representation, with working class people struggling to reach senior roles. This is also the case with regard to disability. Again, there are examples of organisations trying to address some of the inequalities and limited diversity present in some sectors of the industry. One such example is Stage Sight, a network set up to try and promote diversity in the offstage theatre sector. Working with organisations and venues such as the Young Vic and the Disney Theatrical Group, their goal is to showcase "good practice and success in making the off stage workforce more representative of society" (Stage Sight, 2019).

Such local initiatives indicate that sections of the events industry are recognising that lack of diversity in the events workforce is problematic in terms of securing future high quality workers, stimulating innovation and promoting quality. Lack of diversity in terms of who works in events at all levels, and perhaps especially in senior and leadership positions, is a barrier to greater accessibility and inclusion. These are the people who design, commission, and run events, and so drawing on diverse perspectives and experiences of event workers is important if events are to be reflective of broader society and relevant to diverse audiences.

Diversity in audiences can relate to interconnections of power, identity, and possible discrimination with regard to event design, content, and programming. Jarman (2018) discusses the concept of homophily, the propensity to associate with others with whom we are similar. Thus, although events may not be actively trying to be homogenous or exclusionary, this may be the outcome due to unconscious bias of organisers prioritising attendees who have similar heritage, values, and beliefs to themselves and each other. Indeed, he found that better communication from core to periphery could benefit the representation of a more diverse mix of influences (ibid). In the last few decades, funding bodies and cultural organisations, especially in the UK, have been incentivising festivals and public events to diversify programming in an effort to diversify audiences. Although this does not annul long-standing structural inequalities in society, it is an effort to address institutionalised inequity in the cultural sector to some degree. Funding is often based on providing such content, and Finkel (2009) found the addition of different types of activities to 
cultural festivals was based on trying to achieve diversity, inclusion, and audience development goals. This translated to adding more jazz and world music as well as so-called 'ethnic' dance to programmes. She argues that the majority of festivals are not choosing content solely for artistic reasons nor to differentiate themselves from other festivals, but to appear more appealing to potential funding bodies by aligning their programmes with funders' priorities (ibid).

More often than not, so-called 'diversity by design' policies can be counterproductive and paradoxically alienate the very communities that they were strategically trying to include (Duffy et al., 2018). Providing events for certain sections of the population in some sort of tick-box exercise is not an effective way to engage with diverse audiences. Instead, cocreating events with different groups and having them be a part of the event design from the planning stages has been found to be a much more successful approach. As Chambers (2006) argues, the marginalised are experts of their reality and, thus, incorporating more input from affected communities in the events development process allows for more relevant and productive outcomes. Sharp \& Finkel (2018) found this to be the case with the Glasgow 2014 Commonwealth Games, where collaborative working and network creation put in place in the early stages of legacy planning led to more successful community engagement as well as legacy governance and results. Such participatory discussions and forums for active input allow marginalised communities to move from the periphery to the centre in both a psychological and geographic way, allowing for more interactions and potentially turning the event into a more welcoming space for diverse groups (Mackley-Crump \& Zemke, 2019).

Also, as Dashper \& Finkel (forthcoming) suggest, "Societally marginalised communities are not always constrained in event spaces, especially if these events are expressions of their own culture and heritage, where they can feel more of a sense of belonging and community cohesion." Cultural performances are often linked to memories of traditional way of life; yet, they "can allow marginalised groups to explore relationships between self and society as well as issues relating to objectification, exclusion, and identity" (Carlson, 2004, 24). In the UK, events by and for ethnically diverse communities have often included those from Commonwealth countries of the former British Empire such as Afro-Caribbean and South Asian populations. This has translated to carnivals, melas, and Diwali festivals as expressions of diasporic celebrations. For example, much has been written about Notting Hill Carnival over the years (see seminal work by Cohen, 1982; Nurse, 1999; Burr, 2006), and, more recently, Booth (2016) has written about Diwali festivals with regard to identity and diasporic cultures. As Carnegie \& Smith $(2006,255)$ suggest in their study about the Edinburgh mela, "Old cultural reference points battle against new ones as diasporic communities search for internal and external definition, recognition, and their identities as something that is both part of something past, and something future." Such events can act as counterspaces from mainstream hegemonic society (McConnell et al., 2016), providing a sense of identity affirmation and "an avenue to overcome the stigma of marginalisation" (Walters, 2019, 51), which enhance attendees' social capital in empowering ways.

More diversity in promotional materials also is helpful for encouraging wider attendance, as identifying with what is visibly represented can help overcome psychological barriers due to feelings of being 'seen' by event organisations (Aagerup, 2010). How the media represents diverse groups also is influential in establishing event narratives. This can be helpful in terms 
of encouraging more inclusive practices, such as championing women's boxing during the London 2012 Olympic Games, which helped to challenge stereotypes about women in violent sport (Finkel, 2014). Or, on the other hand, the media has the power to restrict more tolerant thinking by playing into old tropes. For example, Domeneghetti (2018) examined articulated notions of femininity by mainstream media during the 2016 Wimbledon Championships and found representations of women constructed in accordance with traditional subordinate, passive, and sexualised roles.

It is widely agreed that event organisers should be aware of the needs of marginalised communities in order to achieve more inclusive practices; however, this is not a 'one size fits all' exercise. According to Walters $(2019,36)$, "Individuals and communities may be/feel marginalised in variety of ways and for a number of reasons, including socio-economic status, ethnicity, race, gender, sexuality, family status, religion, and/or age." Additionally, there can be factors outside these familiar demographic labels that are not usually considered in discussions about diversity, but which also should be included in terms of achieving accessibility and inclusion. For example, recent cross-disciplinary literature in the social sciences has shown that fat women experience weight bias in nearly all aspects of life, including within the fashion industry and, consequently, at fashion events (Crichton \& Finkel, 2019). Thus, individuals are more likely to attend an event if they believe their needs will be met by event facilities, whether this is to do with event spaces (e.g. comfortable seating, spacious toilets); event staff (e.g. sensitivity training); and event representation (e.g. diverse staff and performers).

Given the multitude of diverse groups who could potentially be involved in an event, it is difficult to make much more than generalisations about the best approaches to foster social inclusion. Also, as Walters $(2019,36)$ suggests, "individuals have multiple identities which may compound issues of marginalisation." Therefore, we have set out some issues and provided some examples here, but are aware that there is a need to view this intersectionally and to understand that effective solutions vary on an event by event basis. The primary goal is to work with people, ensuring open communication, to provide safe event spaces for broader communal participation.

\section{Inclusion - How involvement can be realised}

The goal of truly inclusive events is to enable diverse audiences to participate fully in an accessible, comfortable, and enjoyable manner. Yet, despite best intentions, sometimes this is difficult to achieve because along with social aspects, there are also cultural, economic, and political dimensions interwoven in the fabric of inclusionary practices. As Perry \& Sitas (2019) state, "power dynamics in society will play out in cultural spaces, as well as economic and political ones." With regard to events, this raises questions about whose voices are being heard in planning, whose identity is being represented in programming, and who can afford to be involved? For example, Jepson \& Clarke (2013) found that although the original objectives for a festival speak to a rationale of inclusion and openness, this may not be the actual outcome. Their study focusing on a community festival in England showed that when the steering group took control of the development processes without seeking input from local communities, despite inclusive rhetoric, the reality was that the community was largely missing from the festival. This demonstrates the way that event governance and stakeholder politics and power relations can have a significant impact on who is and who is not made to 
feel included in event spaces due to design decisions (e.g. programming content, ticket prices, location, etc.). This, ultimately, can lead to "local cultural identity being defined by the dominant social group" (Jepson \& Clarke, 2013, 14).

Heritage events are another example of this, as they are usually based on a (re)imagining of the past, where there may have been exclusionary relationships and beliefs as the prevailing values of the time. Updating these types of events to align with contemporary expectations of inclusion can often be complicated, as it is seen to alter traditions which can be symbolically tied to certain communities' collective sense of identity. An example of this is American rodeo, which Danby \& Finkel $(2018,199)$ remind us is based on a "romantic retelling of a now idealised way of 'Wild West' frontier life" as part of "mythic symbolism in the North American heritage narrative." By providing celebratory spaces for exemplifying traditional ideas of heteronormative masculinity, Stoeltje $(1981,125)$ argues that rodeo presents "the popular hero of [the frontier] experience, the cowboy, in a live performance." And the emphasis is indeed on the cowboy. At professional American rodeos, women are only allowed to compete in one event, barrel racing, which is based on speed and agility rather than strength and superiority over animals. And it is not solely gender which is the defining exclusionary element of these events. The main professional American rodeo organisation, Professional Rodeo Cowboys Association, features almost all performers, from show actors to clowns to competitors (aside from women's barrel racing as previously mentioned), who identify as white heterosexual cis men. Thus, this narrow segment of representation becomes the dominant retelling of the history of the 'Western frontier' at these heritage events, which can result in 'othering' those who would like to be involved in rodeos but do not feel they would be welcome because they do not share that specific identity. As a result, there are multiple rodeo organisations in the US, which are self-segregated by ethnicity, gender, and sexuality; e.g. there is the Black Rodeo Association, Charreada Rodeo Federation (for Mexican-Americans), Women's Rodeo Association (for mainly white women), Cowgirls of Color, and International Gay Rodeo Association, who all put on their own separate rodeos across the country. In many respects, the kind of segregation displayed at these events reflects broader segregation prominent in contemporary American society. Hence, it can be a challenge to promote inclusive events if the main society is not embracing such ideals either.

Although 'inclusion' is a term that has been adopted widely in cultural, policy, and industry sectors in recent years, especially in the UK, it is worth noting that its meaning encompasses more than solely encouraging attendance. As Finkel et al. $(2018,2)$ state, "Inclusion is an ubiquitous term that should be more contentious than it is currently considered. Inclusion differs from justice in that the former requires people to participate in society as it is constructed, and the latter requires intervention with a redistributive agenda to achieve equality." Miles \& Paddison (2005) suggest that the main goal of social inclusion is to foster participation in the economy and, therefore, is determined by people's relationship to the marketplace. In this way, many recent cultural policies have used festivals and events as vehicles for achieving wider instrumental (non-culturally related) benefits, and, thus, social inclusion strategies can be seen to have a direct connection with economic strategies (Holden, 2006). Through social inclusion programmes, cultural activities, including festivals and events, are expected to yield longer-term economic rewards for many communities (Stevenson, 2004). This is demonstrated by the recent emphasis on volunteer and 
employment skills schemes, youth training programmes, and investment in local infrastructure as a result of mega and major events. For example, Sharp's (2018) study on the 2014 Glasgow Commonwealth Games found that major event volunteer programmes have potential to deepen socio-economic impacts by improving personal wellbeing and providing professional experience.

Additionally, these kinds of socio-economic schemes are often developed with more than the local community in mind. In the past few decades, festivals and events have been adopted by destinations mainly for marketing, tourism, and image enhancing purposes. Event-driven economic development and urban regeneration strategies are well documented in the literature (see Foley et al., 2012; Smith, 2015), with many cities and regions embracing neoliberalist policies to enhance socio-economic benefits by developing festivals and events as part of the urban cultural economy. Often, a result of this is the sidelining of local communities in favour of visitors, which can paradoxically help to publicise and grow an event; yet, by doing so, it can also exclude locals symbolically and physically from their celebrations. As Jepson et al. (2014, 333-4) point out, "Festivals and events are susceptible to a system of cultural production that aims to make the festival product as widely appealing as possible and, in doing so, can change it to a more homogenous or commodified product, which then disconnect from the local communities it set out to serve." It is suggested that over-commercialisation should be avoided in favour of finding a balance which takes into consideration the needs of both locals and tourists in order to create event spaces that are welcoming, meaningful, and also sustainable (Smith, 2015).

An under-examined example of the prioritisation of economic imperatives in destination development and place making purposes concerns the treatment of homeless people during mega and major events. As one of the most vulnerable and impoverished populations, homeless people are not often viewed favourably with regard to event strategic goals and are hardly ever included in event planning. Indeed, some event destinations have actively banished them, such as in Vancouver before the 2010 Winter Olympic and Paralympic Games, where Finkel \& Matheson (2015) were told homeless people were given bus tickets to leave the city to reduce their visibility in public spaces. Similar treatment was also the case in Melbourne before the Australian Open tennis tournament, where homeless camps in the city centre were forcibly removed by police (Wahlquist, 2017). Hubbard \& Sanders (2003) suggest this is to make city spaces more comfortable and welcoming for the middle classes. In this way, social and spatial ordering for such events produces, reproduces, and legitimates dominant moral codes and power relations.

Such examples illustrate that there is still some way to go to have social and economic inclusion become an integral part of all types of events, and this is often due to structural inequalities which exist in mainstream society. According to Quinn $(2005,929)$, "The construction of festival practices is intimately bound up with the cultural and social divisions that structure human population groups." In order to confront and challenge this, Platt \& Finkel $(2018,113)$ suggest, "Structural inequalities need more than tokenism or short term interventions, as these can do more to disguise a problem that erase it all together. Longlasting and meaningful impact and positive change does not happen without this." Whilst delivering truly inclusive events is a challenging prospect, serious consideration of the multifaceted issues of accessibility and diversity, as well as analysis of who is included and 
excluded in all aspects of an event, will help ensure that event planning, design, implementation and impacts are more conducive to achieving greater inclusion within event spaces. Therefore, recognising the importance of embracing diversity and accessibility challenges is a step forward for planning and presenting inclusive events for all.

\section{Conclusions}

Events play a central role in our lives, so prioritising inclusionary planning and practices can invite the re-imagining of our social worlds to involve more fully multicultural and, indeed, multispecies viewpoints. As Danby et al. $(2019,300)$ argue, "Multispecies perspectives are useful for helping us understand the human world better as well, particularly in relation to oppression, exploitation, and inequality." Events environments magnify cultural interactions and social entanglements and, as such, have the potential to facilitate inclusive engagement by creating spaces to bring diverse communities together and to address social, economic, cultural, and political issues. As Perry \& Sitas (2019) argue, "Festivals can respond to community needs when they meaningfully involve residents and create a powerful sense of belonging for people who are historically overlooked." Indeed, it events can provide forums to advance alternative social arrangements and to work as a force for society's transformation, as Warren $(1993,181)$ points out:

"Real life is refracted through, not replaced by, spectacle's prism of fantasy. Under the guise of fantasy, popular culture can make statements about social needs, yet never reveal how truly serious its statements are. It can remain sublimely outside conventional structures of logic and always just beyond the reach of dominant forces. Fantasy's role in popular culture is as a forum where fundamental social anxieties and concerns can be expressed."

There are exciting possibilities for experiences that can be transformative and disruptive; but, in order to do so, they must first be accessible, diverse, and inclusive. With thoughtful planning and transparent communication, event spaces can bring diverse groups of people together to share a commitment to improve lives and places.

\section{References}

Aagerup, U. (2011). The influence of real women in advertising on mass market fashion brand perception. Journal of Fashion Marketing and Management, 14(4), 1361-2026.

Attitude is Everything (2016). Venue and festival charter of best practice. Available from http://www.attitudeiseverything.org.uk/ [Accessed 22/7/19].

BBC News (2018). Festivals 2018: The gender gap in music festival lineups. 03 July. Available at https://www.bbc.co.uk/news/entertainment-arts-44655719 [Accessed 29/07/19].

BCDME (2017). Women in travel, events and hospitality. London: BCD Meetings and Events.

Booth, A. (2016). Negotiating diasporic culture: Festival collaborations and production 
networks. International Journal of Event and Festival Management, 7(2), 100-116. Bourdieu, P. (2010). Distinction: A social critique of the judgment of taste. Abingdon: Routledge.

Burke, R. J., Vinnicombe, S., Singh, V., James, K. (2006). Constructing a professional identity: How young female managers use role models. Women in Management Review, 21(1), 67-81.

Burr, A. (2006). The 'Freedom of the slaves to walk the streets': Celebration, spontaneity, and revelry versus logistics at the Notting Hill Carnival. In Picard, D. \& Robinson, M. (eds.) Festivals, Tourism and Social Change: Remaking Worlds, 84-98. Bristol: Channel View Publications.

CAATA (n.d.) About us. Consortium of Asian American Theaters and Artists. Available from https://caata.net/about/ [Accessed 29/07/19].

Carlson, M. (2004). Performance: A critical introduction. London: Routledge.

Carnegie, E. \& Smith, M. (2006). Mobility, diaspora and the hybridisation of festivity: The case of the Edinburgh Mela. In Picard, D. \& Robinson, M. (eds.) Festivals, Tourism and Social Change: Remaking Worlds, 255-268. Bristol: Channel View Publications.

Caves, R. (2000). Creative Industries: Contracts between art and commerce. Cambridge, MA: Harvard University Press.

Chambers, R. (2006). Transforming power: From zero-sum to win-win? Institute of Development Studies Bulletin, 37(6), 99-110.

Crichton, A. \& Finkel, R. (2019). Barriers to access: Investigation of plus-size women consumer experiences at fashion events. In Walters, T. and Jepson, A. (eds.) Marginalization and events. Abingdon: Routledge.

Cohen, A. (1982). A polyethnic London carnival as contested cultural performance. Ethnic and Racial Studies, 5(1), 23-41.

Danby, P., Dashper, K., Finkel, R. (2019). Multispecies leisure: Human-animal interactions in leisure landscapes. Leisure Studies, 38(3), 291-302.

Danby, P. \& Finkel, R. (2018). Post-humanist investigation into human-equine relational wellbeing: Case of the Rodeo. In Finkel, R., Sharp, B., Sweeney, M. (eds.) Accessibility, Inclusion, and Diversity in Critical Event Studies. Abingdon: Routledge.

Dashper, K. (2013). The "Right" Person for the job: Exploring the aesthetics of labor within the events industry. Event Management, 17(2), 135-144.

Dashper, K. (2018). Confident, focused and connected: The importance of mentoring for women's career development in the events industry. Journal of Policy Research in Tourism, 
Leisure and Events, 10(2), 134-150.

Dashper, K. (2019). Challenging the gendered rhetoric of success? The limitations of women-only mentoring for tackling gender inequality in the workplace. Gender, Work \& Organization. doi.org/10.1111/gwao.12262.

Dashper, K. \& Finkel, R. (forthcoming). 'Doing gender' in Critical Event Studies: A dual agenda for research. Events Management.

Domeneghetti, R. (2018). 'The other side of the net': (Re)presentations of (emphasised) femininity during Wimbledon 2016. Journal of Policy Research in Tourism, Leisure and Events, 10(2), 151-163.

Duffy, M., Mair, J., Waitt, G. (2018). Addressing community diversity: The role of the festival encounter. In Finkel, R., Sharp, B., Sweeney, M. (eds.) Accessibility, inclusion, and diversity in critical event studies, 9-20. Abingdon: Routledge.

Edinburgh Festival Fringe (2019). Putting on an accessible show. Available from https://www.edfringe.com/take-part/putting-on-a-show/accessibility [Accessed 22/7/19].

Euan's Guide (2019). The Edinburgh Festival Fringe. Available from https://www.euansguide.com/campaigns/the-edinburgh-festival-fringe/ [Accessed 22/7/19].

Fadel, L. (2018). Survey suggests 'manels' - all male panels - are still the norm. National Public Radio, 01 November. Available from https://www.npr.org/2018/11/01/663012390/survey-suggests-manels-all-male-panelsare-still-the-norm?t=1564411400703 [Accessed 29/07/19].

Finkel, R. (2009). A Picture of the contemporary combined arts festival landscape. Cultural Trends, 18(1), 3-21.

Finkel, R. (2014). Broadcasting from a neutral corner?: An analysis of the mainstream media's representation of women's boxing at the London 2012 Olympic Games. In Dashper, K., Fletcher, T., McCullough, N. (eds.) Sports events, society and culture. Abingdon: Routledge.

Finkel, R. \& Matheson, C. (2015). Landscape of commercial sex before the 2010 Vancouver Winter Games. Journal of Policy Research in Tourism, Leisure and Events, 7(3), 251-265.

Finkel, R., Sharp, B., Sweeney, M. (eds.) (2018). Accessibility, inclusion, and diversity in critical event studies. Abingdon: Routledge.

Fletcher, T. \& Hylton, K. (2018). 'Race', ethnicity and whiteness in the governance of the events industry. Journal of Policy Research in Tourism, Leisure and Events, 10(2), 164-179.

Foley, M., McGillivray, D., McPherson, G. (2012). Event policy: From theory to strategy. Abingdon: Routledge. 
Frey, B. (2000). The rise and fall of festivals: Reflections on the Salzburg Festival. Working Paper No. 48. Zurich: University of Zurich.

Gans, H. (1999). Popular culture and high culture. New York: Basic Books.

Henderson, E. (2018). Academics in two places at once: (Not) managing caring responsibilities at conferences. In Finkel, R., Sharp, B., Sweeney, M. (eds.) Accessibility, inclusion, and diversity in critical event studies, Chapter 16. Abingdon: Routledge.

Holden, J. (2006). Cultural value and the crisis of legitimacy: Why culture needs a democratic mandate. London: Demos.

Hubbard, P. \& Sanders, T. (2003). Making space for sex work: Female street prostitution and the production of urban space. International Journal of Urban and Regional Research, 27(1), 75-89.

Jarman, D. (2018). Social network analysis and the hunt for homophily: Diversity and equality within festival communities. Journal of Policy Research in Tourism, Leisure and Events, 10(2), 117-133.

Jepson, A. S., \& Clarke, A. (2013). Events and community development. In Finkel, R., McGillivray, D., McPherson, G., Robinson, P. (eds.) Research themes for events, 6-18. Wallingford: CABI.

Jepson, A., Clarke, A., Ragsdell, G. (2014). Investigating the application of the motivationopportunity-ability model to reveal factors which facilitate or inhibit inclusive engagement within local community festivals. Scandinavian Journal of Hospitality and Tourism, 14(3), 331-348.

Langen, F. \& Garcia, B. (2009). Measuring impacts of cultural events. Liverpool: Impacts08.

McConnell, E. A., Todd, N. R., Odahl-Ruan, C., Shattell, M. (2016). Complicating counterspaces: Intersectionality and the Michigan Womyn's Music Festival. American Journal of Community Psychology, 57(3-4), 473-488.

McGuigan, J. (1996). Culture and the public sphere. Abingdon: Routledge.

Mackley-Crump, J. \& Zemke, K. (2019). The FAFSWAG Ball: Event spaces, countermarginal narratives and walking queer bodies into the centre. In Walters, T. \& Jepson, A. (eds.) Marginalization and events, 95-109. Abingdon: Routledge.

Meier, M. (2015). The value of female sporting role models. Sport in Society, 18(8), 968-982.

Miles, S. and Paddison, R. (2005). Introduction: The rise and rise of culture-led urban regeneration. Urban Studies, 42(5/6), 833-839. 
Morgan, A. \& Condliffe, S. (2006), Measuring the economic impacts of convention centers and event tourism. Journal of Convention \& Event Tourism, 8(4), 81-100.

Morgenroth, T., Ryan, M. K., Peters, K. (2015). The motivational theory of role modeling:

How role models influence role aspirants' goals. Review of General Psychology, 19(4), 465483.

Misener, L., McGillivray, D., McPherson, G., Legg, D. (2015). Leveraging parasport events for sustainable community participation: The Glasgow 2014 Commonwealth Games. Annals of Leisure Research, 18(4), 450-469.

Newbold, C., Jordan, J., Kelly, P., Diaz, K. (2019). Principles of festival management. Oxford: Goodfellow Publishers.

Nurse, K. (1999). Globalization and Trinidad Carnival: Diaspora, hybridity and identity in global culture. Cultural Studies, 13(4), 661-690.

O'Brien, D., Laurison, D., Miles, A., Friedman, S. (2016). Are the creative industries meritocratic? An analysis of the 2014 British Labour Force Survey. Cultural Trends, 25(2), 116-131.

Padavic, I., Ely, R. J., Reid, E. M. (2019). Explaining the persistence of gender inequality: The work-family narrative as a social defense against the 24/7 work culture. Administrative Science Quarterly, 0001839219832310.

Perry, B. \& Sitas, R. (2019). Festivals can transform cities by making space for overlooked people and cultures. The Conversation, 15 August. Available from

https://theconversation.com/festivals-can-transform-cities-by-making-space-foroverlooked-people-and-cultures-

121013?utm medium=Social\&utm source=Twitter\#Echobox=1565888022 [Accessed 16/8/19].

Platt, L. \& Finkel, R. (2018). Introduction: Equality \& diversity in professional planned events industry. Journal of Policy Research in Tourism, Leisure and Events, 10(2), 113-116.

Preuss, H. (2007). The conceptualisation and measurement of mega sport event legacies. Journal of Sport \& Tourism, 12(3-4), 207-228.

PRS Foundation (2019). 250+ music organizations commit to Keychange 50:50 pledge. Available from https://keychange.eu/blog/250-music-organisations-commit-tokeychange-50-50-pledge/ [Accessed 29/07/19].

Quinn, B. (2005). Arts festivals and the city. Urban Studies, 42(5/6), 927-943.

Robertson, M., Ong, F., Lockstone-Binney, L., Ali-Knight, J. (2018). Critical event studies: Issues and perspectives. Event Management, 22, 865-874.

Rodríguez-Zulaica, A. \& Fernández-Villarán Ara, A. (2018). Measuring accessibility in MICE 
venues: The case of the Euskalduna Conference Centre (Bilbao, Spain). In Finkel, R., Sharp, B., Sweeney, M. (eds.) Accessibility, inclusion, and diversity in critical event studies, Chapter 15. Abingdon: Routledge.

Sharp, B. (2018). Volunteering and wellbeing: A case study of the Glasgow 2014 Commonwealth Games volunteer programmes. In Finkel, R., Sharp, B., Sweeney, M. (eds.) Accessibility, Inclusion, and Diversity in Critical Event Studies. Abingdon: Routledge.

Sharp, B. \& Finkel, R. (2018). Governing major event legacy: Case of the Glasgow 2014 Commonwealth Games. Event Management, 22(6), 903-915.

Smith, A. (2015). Events in the city: Using public spaces as event venues. Abingdon: Routledge.

Snapes, L. (2019). Lewis Capaldi arena tour pledges help for fans with anxiety. The Guardian, 18 April. Available from https://www.theguardian.com/music/2019/apr/18/lewis-capaldi-arena-tour-help-fansanxiety-escape-room [Accessed 22/7/19].

Stage Sight (2019). New network to improve diversity of theatre workforce announced. 28 March. Available from https://uktheatre.org/theatre-industry/news/stage-sightannounced/ [Accessed 30/07/19].

Stevenson, D. (2004). 'Civic gold' rush: Cultural planning and the politics of the Third Way, International Journal of Cultural Policy. 10, 119-131.

Stoeltje, B. (1981). Cowboys and clowns: Rodeo specialists and the ideology of work and play. In R. Bauman and R. Abrahams (eds.) 'And other neighborly names': Social processes and cultural image in Texas folklore, 123-151. Austin: University of Texas Press.

Strom, E. (2002). Converting pork into porcelain: Cultural institutions and downturn development. Urban Affairs Review, 38(1), 3-21.

Thomas, R. (2017). A remarkable absence of women: A comment on the formation of the new Events Industry Board. Journal of Policy Research in Tourism, Leisure and Events, 9(2), 201-204.

Wahlquist, C. (2017). Melbourne city council denies homeless camps 'cleanup' linked to Australian Open. 11 January. Available from https://www.theguardian.com/australianews/2017/jan/11/melbourne-city-council-denies-homeless-camps-cleanup-linked-toaustralian-open [Accessed 15/8/19].

Walters, T. (2018). A tripartite approach to accessibility, diversity, and inclusion in academic conferences. In Finkel, R., Sharp, B., Sweeney, M. (eds.) Accessibility, inclusion, and diversity in critical event studies, Chapter 17. Abingdon: Routledge.

Walters, T. (2019). 'Proud to be South D': Perceptions of a street festival in a marginalised 
community in New Zealand. In Walters, T. \& Jepson, A. (eds.) Marginalisation and events, 36-54. Abingdon: Routledge.

Walters, T. \& Jepson, A. (eds.) Marginalisation and events. Abingdon: Routledge. Warren, S. (1993). 'This heaven gives me migraines': The problems and promise of landscapes of leisure. In Duncan, J. \& Ley, D. (eds.) Place/Culture/Representation, 173-186. Abingdon: Routledge.

Wolfe-Robinson, M. (2019). Grassroots project addresses Edinburgh Fringe's 'overwhelming whiteness'. The Guardian, 29 July. Available from https://www.theguardian.com/stage/2019/jul/29/grassroots-project-addressesedinburgh-fringes-overwhelming-whiteness [Accessed 29/07/19].

Wood, E. (2005), Measuring the economic and social impacts of local authority events. 